\title{
Assessing the outcomes of anti-money laundering policies. Ambitions and reality
}

\author{
Brigitte Slot and Linette de Swart ${ }^{1}$
}

\section{Introduction}

Combatting money-laundering ranks highly on the political agenda, both internationally and in the Netherlands. Much effort has been put into the prevention of money laundering, as well as detecting and prosecuting criminals who actually have spent their ill-gotten money in the legal economy. Not only has the legal framework been strengthened, e.g. the implementation of the fourth anti-money laundering directive and fine-tuning of the Dutch Penal Code, several financial programs have been introduced in order to strengthen the position of both the police and special investigators as well as the public prosecution. In addition, cooperation between the public and private sector is encouraged and several informal and formal networks combatting money laundering have been established.

Anti-money laundering policies are part of the political agenda and many resources have been made available - both in terms of public money and human capacity. However, it is unknown what the impacts of these actions are on money laundering in particular and on crime in general. The Financial Action Task Force (FATF) has recently set-up a framework for assessing the effectiveness of anti-money laundering policies. In their fourth round of mutual evaluations, this new framework is applied for the first time. The mutual evaluation of the Netherlands is planned for 2020. In preparation of the coming mutual evaluation, the Dutch Ministry of Justice commissioned a study to investigate the extent to which the activities

1 Both authors are researchers at Ecorys Netherlands. 
and the actual outcomes of the anti-money laundering policies in the Netherlands comply with the objectives of the anti-money laundering policies as formulated by the FATF. ${ }^{2}$ This chapter highlights the main outcomes of this exercise.

\section{Anti-money laundering in perspective}

The Financial Action Task Force (FATF) was created in 1989 by the G-7 ${ }^{3}$ with the goal of combatting money laundering as a strategy in the fight against drugs. After the attacks on the World Trade Centre in 2001, terrorism financing was added to the FATF mandate. In 2008, the FATF scope was further extended to the financing of proliferation of weapons of mass destruction.

Central to the FATF architecture are the 40 Recommendations, which provide international standards on how countries should organise their fight against money laundering and terrorist financing, as well as the financing of proliferation. Countries shall implement and adapt these standards to their specific legal and institutional circumstances and characteristics of their financial sector. ${ }^{4}$

The FATF Recommendations refer, amongst others, to establishing well-functioning financial intelligence unit, pursuing risk-based policies and having an operational sanctioning system. The extent to which a country has implemented the Recommendations is evaluated via a system of regular mutual evaluations, in which, per Recommendation, the evaluators

2 This study is a follow-up of an earlier study that also aimed to assess the state of play of the Dutch anti-money laundering system. That study, prepared by Decide in 2015, provides information for the period $2010-2013$ and is seen as a snapshot of anti-money laundering policies in that period.

3 Canada, France, Germany, Italy, Japan, the United Kingdom and the United States of America.

4 Implementation of the FATF recommendations in the European Union is regulated via the EU Anti-Money Laundering Directives of which the first was adopted in 1990. The current fourth iteration of the EU Anti-Money Laundering Directive was published on 5 June 2015. The fifth will come into force on the 10th January 2020. 
indicate whether the country is either largely compliant, partially compliant or not compliant at all. To pass the evaluation successfully, countries are urged to remedy any biases and strategic deficiencies.

The 40 FATF Recommendations primarily focus on the 'technical' aspects of their anti-money laundering and terrorist financing architecture. It concentrates primarily on the question whether countries have the required legal and institutional frameworks in place and whether their competent authorities have sufficient powers to prevent and fight money laundering, terrorism financing and proliferation in an internationally harmonised manner.

This system of technical compliance only indicates whether certain measures, laws and institutions are in place. The system does not provide any insights into the effectiveness of the deployed systems. Alternatively, the system does not indicate whether less money was laundered, terrorism and proliferation were prevented or more criminals were caught as a result of the measures.

This implies that establishing the right FATF-approved system does not automatically imply that money laundering and terrorist financing are addressed successfully. In a paper on the merits and downsides of the FATFapproach Halliday et al., (2014) conclude that the FATF has been very successful in establishing global standards in anti-money laundering and terrorist financing regimes. However, at the same time the FATF is remarkably vague and generic in its objectives and how to get there. The FATF Recommendations are based on a 'belief' that money laundering and the financing of terrorism are more likely to be reduced if countries comply with the FATF requirements (Halliday et al., 2014).

This chapter focuses on the FATF-approach towards money laundering. The core question is: to what extent does the FATF provide sufficient guidance on assessing the results of their own anti-money laundering regime.

\section{New ambitions}

Building upon a successful worldwide implementation of the FATF regime, the FATF realises that the extent to which its overall objectives are being achieved is still an open question. In order to address this omission, 
and to thereby reach a 'next level' of country assessments, the FATF revised its evaluation system in 2012 (FATF, 2012). Next to the 40 technical Recommendations, which were reviewed simultaneously, the FATF adopted a new system to measure the effectiveness of national anti-money laundering.

First a 'high-level objective' was formulated, which echoes the 'raison d'être' of the FATF by stating that: "Financial systems and the broader economy shall be protected from the threats of money laundering and the financing of terrorism and proliferation, thereby strengthening financial sector integrity and contributing to safety and security."

This high-level objective still raises many unresolved conceptual questions, such as the meaning of the term 'money laundering', which is not unproblematic as legal definitions differ from the colloquial use of the term money laundering, and countries also vary in their criminal code definitions of the phenomenon. Secondly, one may still question what is meant by the supposed 'threat of money laundering to the financial system.' For example, Van Duyne and Soudijn, 2013 argue that money of a criminal will function no differently in the bank than an account with legally acquired money. ${ }^{5}$

In order to specify the generic high level objective, three 'intermediate outcomes' and eleven 'immediate outcomes' have been formulated. The first eight immediate outcomes directly relate to fighting money laundering, while immediate outcomes nine to eleven focus on combatting terrorism and proliferation financing (see Figure 1).

5 As put differently by the authors: the excavated Viking silver hoards in Britain were less threatening than the Vikings themselves (Van Duyne and Soudijn, 2013). 


\section{Figure 1.}

\section{FATF Framework for evaluating effectiveness}

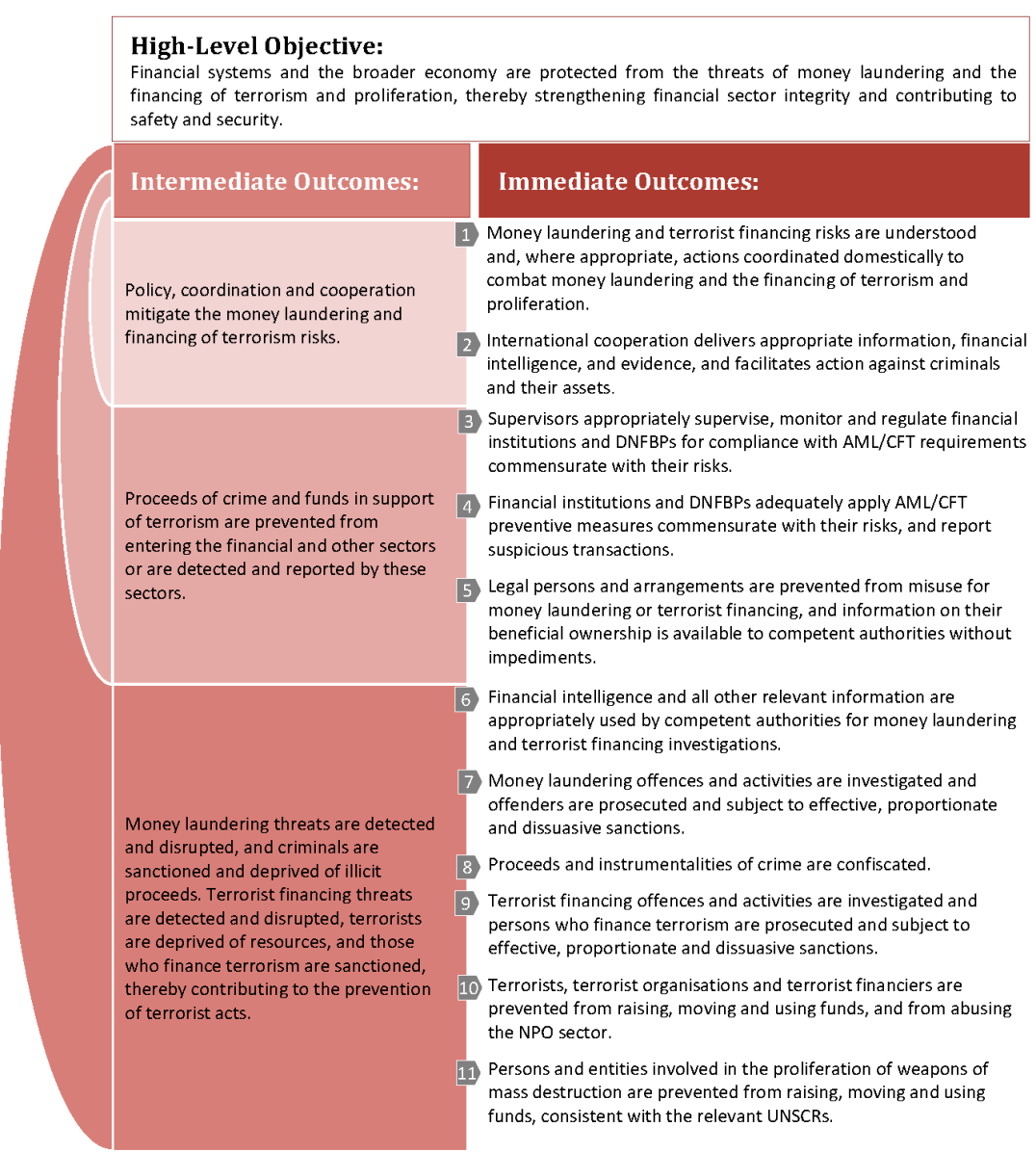

Source: FATF Methodology (2013)

The new FATF effectiveness-assessment methodology was adopted in 2013 (FATF, 2013). In order to operationalise how effectiveness shall be achieved, for each of the immediate outcomes multiple 'core issues' were formulated. And to strengthen the system even further, the FATF issued a guidance document on data requirements in which, per core issue, several data suggestions are provided (FATF, 2015).

As described above, the FATF developed an extensive Framework for evaluating the effectiveness of national anti-money laundering systems. By linking the different FATF publications, a concise evaluation framework 
becomes apparent. Below is an example of one core issue combined with the data suggestions and linked to the relevant immediate outcome is presented.

\section{Figure 2.}

\section{Combining the FATF documents into one evaluation framework}

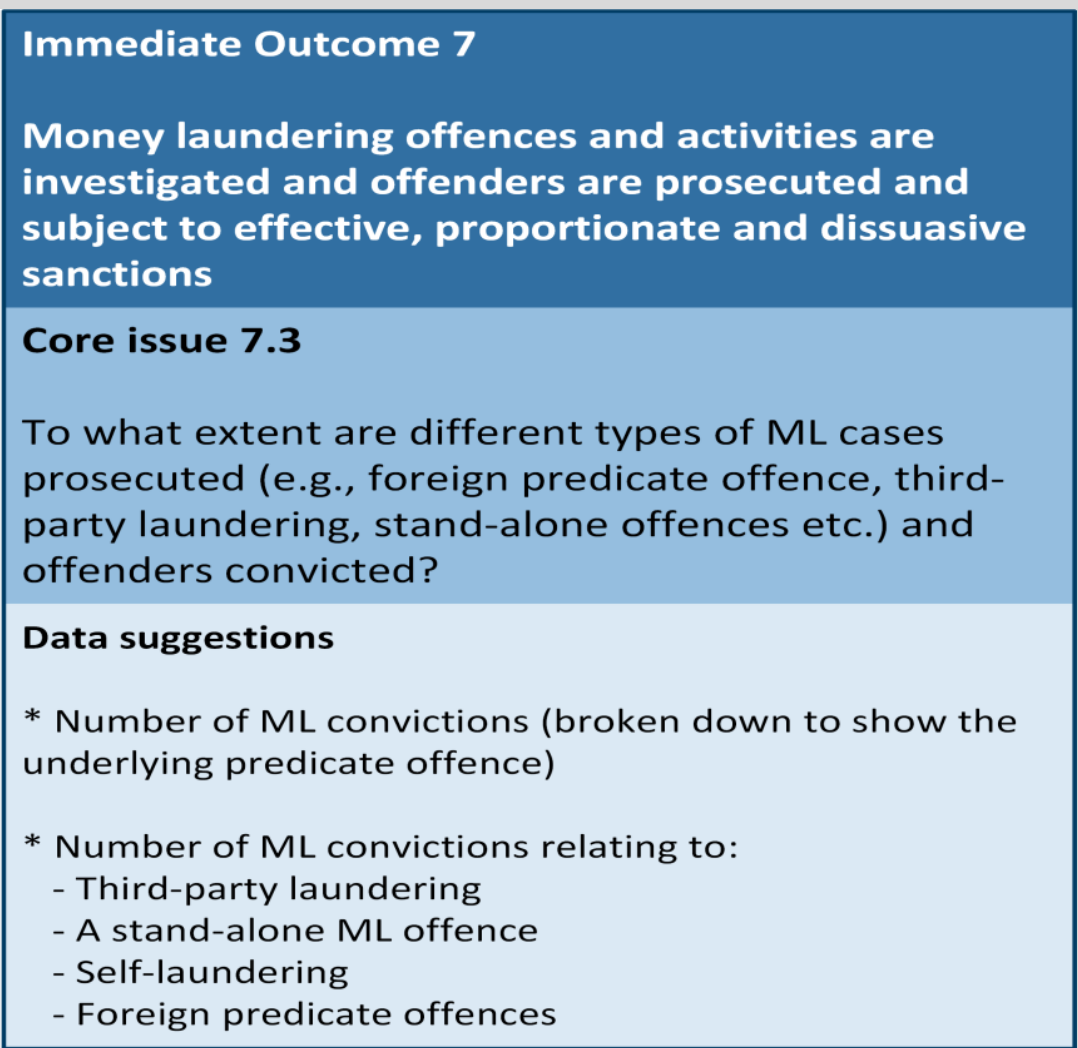

Source: FATF $(2012,2013,2015)$

With this new methodology, the FATF's focus is changing from a predominantly technical evaluation of laws and systems to a more mixed evaluation in which outcomes of anti-money laundering investigations and prosecutions are systematically being assessed. This new approach is applied in the fourth round of mutual evaluations that started in 2013. More concretely, each mutual evaluation shall also analyse the actual results ('outcomes') of time and money invested in fighting money laundering. The 
question is whether, and to what extent, the new FATF methodology provides sufficient guidance to do so.

\section{Anti-money laundering in the Netherlands}

Anti-money laundering policies in the Netherlands have two interrelated goals: (i) the prevention and fight against crime, and (ii) the protection of the integrity of the financial sector. The Netherlands does not have an overall national anti-money laundering policy framework, for example, as it is embedded in its national anti-organised crime policies on the one hand, and policies aimed at stimulating financial integrity on the other hand. The two responsible ministries are the Ministry of Justice (organised crime section) and the Ministry of Finance (financial sector integrity).

Strictly speaking, this complicates the assessment of the effectiveness of the anti-money laundering measures. The successes of anti-money laundering policies strongly depend on how successful a country (the Netherlands) is in preventing and fighting crime in general. Similarly, stimulating financial integrity is the result of a complex set of rules of conduct and of financial surveillance measures, which is much wider than the fight against money laundering alone. Anti-money laundering policies cannot, in other words, be assessed on their own merits alone.

The fourth FATF-evaluation of the Netherlands is scheduled from October to November 2020. In order to start timely preparations of this evaluation, and with the objective to gauge its own anti-money laundering policies on a regular basis, the Ministry of Justice commissioned the development of an 'Anti-money laundering policy monitor' (Ecorys, 2018). One of the specific objectives of this monitor was to explore the application of the new FATF-effectiveness assessment to the situation in the Netherlands. The monitor covers the years $2014-2016$.

\section{Methodology of the monitor}

The research conducted in the context of this monitor consisted of a comprehensive literature review of (Dutch and international) academic literature and policy documents, the collection and analysis of publicly available 
quantitative data, and interviews with a large number of relevant stakeholders from Dutch policymaking and anti-money laundering circles.

The monitor's core unit of measurement is derived from an analysis of actors within the anti-money laundering enforcement network in the Netherlands, including: various supervisory agencies, the Financial Intelligence Unit (FIU-Nederland), the National Police, the Dutch Fiscal Information and Investigation Service (FIOD), the Anti Money Laundering Centre (AMLC), the Prosecutors Office and Judiciary, the Central Judicial Debt Collection Agency (CJIB), national customs agencies, and the Ministries of Justice and Finance.

For each actor, a comprehensive overview was prepared, describing their role in the anti-money laundering system, their goals, the available resources (both in terms of FTE and in terms of financial means), their main activities and the results thereof. Where possible, a comparison between the period 2010 - 2013 and the period 2014 - 2016 was made.

Based on these individual analyses, an assessment of the overall Dutch anti-money laundering system was made. In this analysis, the FATF framework was tested and for each data suggestion and core issue an indication is provided as to whether it is possible to provide the requested information.

\section{Main findings}

\section{a. from a practical research perspective}

Collecting the information required by the FATF is a challenging task, especially for independent researchers. Over a period of almost two years with multiple interviews per actor, phone calls and emails, the amount of information collected remained limited. Traditional data, such as the number of suspicious transaction reports (STRs), the number of convictions, and the amount of confiscations can be retrieved rather easily. Nevertheless, when more details are required, such as the type of money laundering offence, ${ }^{6}$ the sanction imposed and the number of police investigations, it already becomes more difficult.

6 For instance, self-laundering or third party laundering. 406 
On the one hand, actors are reluctant to share information. Some indicated that sharing requested information would be contradictory to the confidentiality of the data (e.g. on administrative sanctions imposed by the supervisory agencies), while others did not wish to collaborate with independent researchers. On the other hand, much of the data requested by the FATF is simply not available within the organisations. For each of the data suggestions (FATF, 2015), an assessment was made about which actor should have the required information. Several of the actors indicated that they do not collect the information requested and in some cases they also pointed out that they do not see the relevance of collecting such information. It should be noted that the Netherlands is, compared to many other countries, well above average in the presentation and analysis of judicial data (Levi et al., 2017).

Overall, collecting quantitative data to assess the effectiveness is a time consuming and difficult task. Much of the requested information is not available or actors are not willing to share this. From this practical point of view, assessing the effectiveness of the Dutch anti-money laundering system turned out to be impossible. Some indications of the results obtained could be given, but assessing whether or not the efforts made are effective, is still an open-ended question.

\section{b. from a more theoretical perspective}

Difficulties with the effectiveness assessment did not only derive from a lack of data, as described above. Even when it would have been possible to collect all the required data, an analysis of the effectiveness of the antimoney laundering system would have remained a methodological obstacle. Several, more essential problems, will remain and need to be addressed, namely:

- There is no credible methodology for measuring the total amounts of money laundered;

- The FATF overlooks the need for constructing a proper baseline or zero measurement;

- Data, as suggested by the FATF, allow different and even contradictory conclusions;

- Prevention is not sufficiently delineated by the new FATF-methodology, which renders it unmeasurable; 
- The FATF implicitly assumes a predominantly criminal law approach to money laundering.

In the following paragraphs, examples are presented to illustrate the above stated points. This is based on the earlier mentioned study for the Dutch Ministry of Justice (Ecorys, 2018).

First, quantification of the outcomes (effectiveness) is problematic as long as it remains unknown how much money is actually being laundered. Despite several attempts to assess the size of the money laundering, no unequivocal methodology for measuring money laundering has been provided thus far. Attempts to quantify the total amount of money laundered - see for example Tanzi (1996), Schneider (2004, 2015) Unger (2006, 2018), Soudijn (2012) - are based on numerous assumptions and econometric modelling, which create much discussion, both within academia and among policymakers. These estimates are too uncertain for assessing the effectiveness of anti-money laundering policies over the years.

None of the methods is based on the extrapolation of prosecution data and for good reasons. First prosecution data are not useful in assessing the amounts of money laundered. One of the problems with prosecution data is that the prosecutor can by default impose money laundering for any crime-for-profit. Public prosecutors do not always follow this route, because (i) the extra burden of proof needed for a money laundering charge has no added value in terms of sentencing; (ii) charging money-laundering offences might unnecessarily reasons slow down the trail efficiency and (iii) the proceeds of crime may be reclaimed with demanding a court recovery order or sentence.

Second, to assess the effectiveness of anti-money laundering measures a baseline is required. Such a baseline is not part of the current FATF methodology, while a baseline is a critical reference point for assessing the changes due to anti-money laundering activities and for understanding the effectiveness of an anti-money laundering regime. The current fourth round of mutual evaluations should explicitly have aimed to provide a baseline for future effectiveness assessments. Strictly speaking, without a baseline no proper judgements on the effectiveness can be made. The FATF seems to have overlooked this.

Third, the FATF presents numerous data suggestions to substantiate the immediate outcomes (FATF, 2015). In its guidance, the FATF indicates 
that an assessment of the effectiveness should be beyond a purely statistical exercise. Assessors should use data and statistics, as well as other qualitative information, when reaching an informed judgement about how well an outcome is being achieved. Data should be 'interpreted critically' and placed in the context of a country's circumstances. This is another core problem of the new methodology. The suggested approach appears to be based on 'hard data', but in the end, the interpretation is fully qualitative and subjective. This is in line with a general contemporary critique in social sciences on the tendency to overvalue statistics and to undervalue the validity thereof (Levi et al., 2017).

In addition, country reports of the fourth round of mutual FATF evaluations conducted thus far, reveal a remarkable lack of data. Also a variation between countries in types of data presented, and in the levels of detail thereof, became apparent. A short analysis of a selection country reports ${ }^{7}$ shows that:

- None of the countries presented data in the context of Immediate Outcome (IO) 1 (anti-money laundering policy framework).

- The narratives of IO 6,7 and 8 (detection, prosecution and sanctioning respectively) are most data rich.

- Data are being used multiple times to explain more than one IO.

- Assessments of IO 3 (supervisors) highly depend on the internal data made available by specific supervisors, while there is wide variation across countries on how supervision is organised, which complicates cross-country comparisons.

- The level of detail between the presented data differs substantially across countries and across types of data. Nevertheless, more detailed data do not automatically lead to a higher evaluation result. ${ }^{8}$

- There is no proper validity test of the presented data, which makes them questionable for evaluation purposes.

The availability of data as suggested by the FATF-methodology is also

7 In the context of the study for the Ministry of Justice, the following country reports were analysed: Austria, Australia, Belgium, Canada, Hungary, Italy, Norway, Spain, Sweden, Switzerland and USA.

8 During a mutual FATF evaluation, all immediate outcomes are assessed. Based on the assessment, the country receives per immediate outcome an effectiveness mark, e.g. low, moderate or substantial level of effectiveness'. The assessment is based on both quantitative and mainly qualitative information. How these are combined remains undeterminated. 
a problem in the Netherlands. Two years before the fourth mutual evaluation of the Netherlands, much of the data, as suggested in the FATF-assessment methodology, were not (yet) available.

A more pressing pitfall is that the data may tell different and even opposing stories. For instance, what does a high number of money laundering cases prosecuted (core issue 7,3) mean? Is this an indication that money laundering is actively and successfully detected, investigated and prosecuted? Or is the underlying problem so large, that in practice the efforts made are only a drop in the ocean? Reversing this argument, does a low number of money laundering cases mean that crime is not actively detected and prosecuted? Or is the problem simply of a limited dimension? Or is there an successful level of prevention?

Another example concerns the implicit message in many of the FATF evaluations is that a high number of STRs or an increase in the number of STRs is considered as a sign of a good or better functioning anti-money laundering system. However, an increase in STRs may reflect several developments. It may point at enhanced FATF-compliance, as more cases of suspected money laundering are reported to the authorities. It could also be the result of an increase in underlying money laundering activities. Changes in the numbers of STRs may also simply result from a change in anti-money laundering regulations, for instance when new reporting entities are brought under the anti-money laundering regulations. This illustrates that a good understanding of the context is crucial to draw conclusions on the real-world meaning of the data.

In addition, the number of money laundering cases detected, investigated, prosecuted or money laundering convictions does not take into account the size, nature and complexity of the cases. As an example, Figure 2 presents the number of money laundering cases prosecuted in the Netherlands in the period 2010 to 2016 . The data reveal a decrease between 2012 and 2015. What does this mean? Was the Dutch public prosecution doing less well? Without any additional information, the question cannot be answered unambiguously. It is possible, that the public prosecution focused on several larger and more complicated cases. Successful prosecution of such complex cases may yield better results in terms of discouraging money laundering practices than prosecuting multiple smaller cases such as the many cases of 'self-laundering': the small fry that feeds the statistics. Nevertheless, the FATF data suggestions seem to favour a high 410 
number of cases prosecuted above the prosecution of a more limited number of large and complex cases. A deliberate focus on the latter, might in an evaluation falsely be labelled as a less effective policy.

\section{Figure 3}

Number of money laundering cases prosecuted

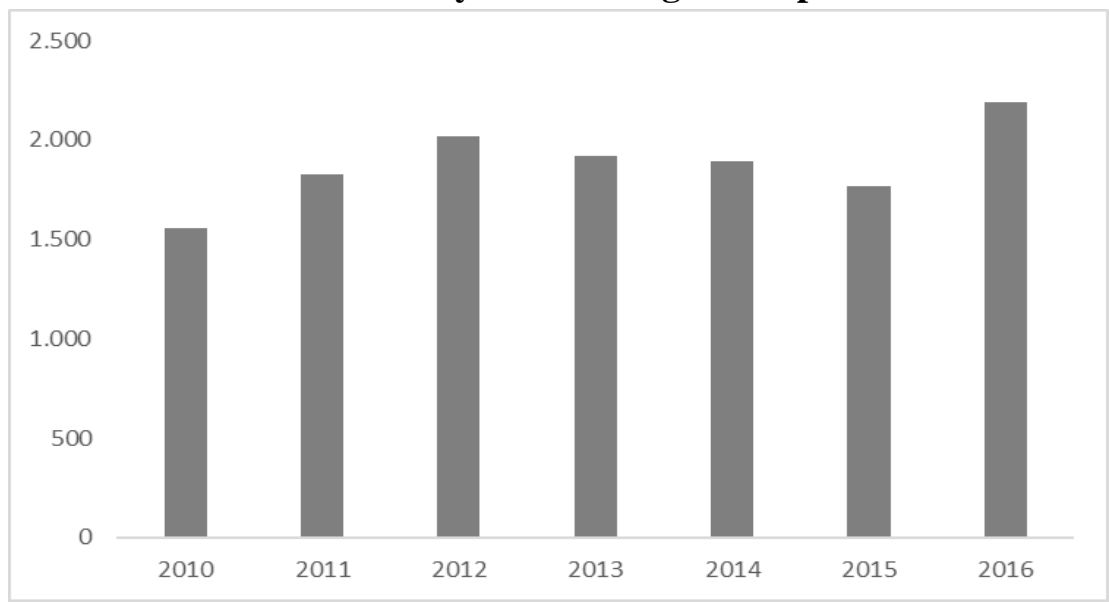

Source: Ecorys (2018)

Fourth, assessing prevention is problematic. Prevention is an important pillar under anti-money laundering policies and practices. The second intermediate outcome explicitly refers to prevention, by stating that proceeds of crime shall be prevented from entering the financial and other sectors. Prevention is explicitly referred to in immediate outcome 4 according to which financial institutions and other economic entities have to apply adequate anti-money laundering preventive measures. Immediate outcome 5 also refers to the prevention of misuse for money laundering.

As an illustration, stakeholders in the Netherlands claim that the focus in the fight against money laundering is shifting towards an increase in activities aimed at prevention. Many of the stakeholders interviewed in the context of this study indicated that more time and resources have been devoted to make the Netherlands an unattractive country for money laundering. Nevertheless, it is difficult to support these statements, as determining the impact of these efforts is difficult, especially in a quantitative way. ${ }^{9}$

9 Evaluating crime prevention is a developed area of research within criminology. A variety of different approaches to measures crime prevention outcomes 
The FATF itself hardly provides any guidance on this issue, as the most elaborated core issues still focus on detecting and prosecuting money laundering activities, and not on preventing it. Based on the information collected in the Netherlands, it is not possible to indicate how much money laundering was prevented, which share of it directly relates to anti-money laundering policies and how much is caused by external factors measured from a determined point in time. Again, a prevention assessment without a baseline (zero-measurement) is void.

Connected to the above argument is the fact that money-laundering activities might change and thereby slip off the detection radar. For example, the methods to launder the money might change to a yet unknown area for the relevant authorities or, more importantly, money-laundering activities might move to other countries, with less stringent regimes. Increasing national efforts to combat money-laundering lead to an increased pressure on the systems of other (often neighbouring) countries. As a result, international cross-border cooperation becomes more important in the fight against crime. Although many stakeholders, including the European Commission and the FATF, recognise the importance of cross-border cooperation, reality shows that international cooperation remains a struggle.

Finally, the FATF-methodology for assessing the effectiveness of antimoney laundering policies implicitly assumes a predominant criminal law approach. Although the FATF indicates that, the data suggestions are not exhaustive and not mandatory, the new evaluation system still has a criminal law bias. There are no data suggestions on alternative repressive approaches, which in fact might be highly effective. For example, a multitude of sanctions can be taken against perpetrators of money laundering, making use of instruments available under criminal law, administrative law, fiscal law and disciplinary law. In the different areas, fines can be imposed and the values of those fines can be combined. However, in administrative law also other sanctions might be imposed, such as the revoking of licenses. These measures might be more effective in combatting money laundering than imposing fines. Nonetheless, they are easily forgotten in the effectiveness assessment, as it is easier to count convictions or euros confiscated

have been developed, including experimental research designs, qualitative research, participatory evaluations and theory driven approaches (see Morgan and Homel, 2013). These methods could potentially enrich the FATF approach to measure the preventive effectiveness of the anti-money laundering regime. 
than assessing the impact of an individually revoked permit.

\section{Conclusions}

The FATF has been successful in establishing global standards in antimoney laundering laws, institutions and polices. Since 2012, the FATF evaluation system not only focuses on technical compliance to the FATF standards but also on the effectiveness of the deployed systems. This new approach is currently implemented in the fourth round of mutual evaluations.

Despite these valid intentions, the application of the new FATF evaluations evaluation framework to real world anti-money laundering activities raises many questions.

Assessing the impact of anti-money laundering policies is by definition a challenge as there is no methodology for measuring the size of the underlying problem (the amounts of money that are actually being laundered in a country).

Besides this core problem, two aspects of the new methodology should be addressed in order to further improve the effectiveness assessment method. One the one hand, the FATF data suggestions centre around traditional - and relatively easy-to-get - data, such as numbers of suspicious transaction reports, money laundering investigations and prosecutions. These data may be interpreted in contradictory directions. For example, an increase in STRs may be the result of both enhanced and weaker antimoney laundering policies, and of an increase of the underlying problem. The conclusion is that 'hard data' become soft, as a qualitative and sometimes subjective interpretation is needed. Moreover, anti-money laundering policies and practices are changing rapidly in some countries, such as the Netherlands, where a traditional judicial approach to money laundering is replaced by a combination of penal, fiscal and administrative instruments. This should be better addressed in the FATF evaluation framework.

On the other hand, several methodological challenges are open to be addressed in the future. First of all, as prevention is crucial in the international anti-money laundering regime a credible method for assessing the preventive impacts would be greatly enhance the effectiveness assessment framework. Also, the FATF should develop guidance on validation of the 
presented data. In addition, the FATF effectiveness assessment would become more credible with the explicit introduction of a baseline assessment.

In order to address the current weaknesses in the FATF evaluation methodology, the FATF should appoint a panel of independent academic experts and assign them with the task to address current data and methodological shortcomings. The current FATF system of a high-level objective, intermediate outcomes and immediate outcomes is predominantly the result of international negotiations, rather than strict analytical thinking. This is the fundamental shortcoming of the current methodology. The interpretation of the evaluation outcomes may be subject to politics while evaluation methodologies are non-negotiable by definition.

\section{References}

Ecorys, Monitor anti-money laundering 2014 - 2016, 2018.

Ecorys, University of Utrecht and Free University of Amsterdam, Amount and effects of criminal expenses, 2018.

FATF, International standards on combating money laundering and the financing of terrorism \& proliferation - The FATF recommendations, 2012.

FATF, Methodology for assessing technical compliance with the FATF recommendations and the effectiveness of AML/CFT systems, 2013.

FATF, FATF guidance - AML/CFT-related data and statistics, 2015.

Halliday, T.C., M. Levi and P. Reuter, P., Global surveillance of dirty money: assessing assessment of regimes to control money-laundering and combat the financing of terrorism, 2014.

Levi, M., P. Reuter and T.C. Halliday, Can the AML system be evaluated without better data?, 2017

Morgan, A. and P. Homel, Evaluating crime prevention: Lessons from large-scale community Programs. Australian Institute of Criminology, trends and issues in crime and criminal justice, No. 458, 2013.

Schneider, F., The size of the shadow economies of 145 countries all over the world, 2014. 
Schneider, J.F., Size and development of the shadow economy of 31 European and 5 other OECD countries from 2003 to 2015: different developments, 2015.

Soudijn M.R.J. \& Th. Akse, Witwassen. Criminaliteitsbeeldanalyse KLPD, Dienst Nationale Recherche, 2012.

Tanzi, V., Money laundering and the international financial system, IMF working paper, Number 96/55, 1996.

Unger, B., G. Rawlings, M. Busuioc, J. Ferwerda, M. Siegel, W. de Kruijf and $\mathrm{K}$. Wokke, The amounts and the effects of money laundering. Den Haag: Ministerie van Financiën, 2006.

van Duyne, P.C. and M.R.J. Soudijn, Crime money in the financial system - What we fear and what we know, 2010.

van Duyne, P.C., J.H. Harvey and L.Y. Gelemerova, The critical handbook of money laundering - policy, analysis and myths. London: Palgrave, 2019. 